Prestroke CHA(2)DS(2)-VASc Score and Severity of Acute Stroke in Patients with Atrial Fibrillation : Findings from RAF Study

\title{
Acciarresi, Monica
}

2017-06

Acciarresi , M , Paciaroni , M , Agnelli , G , Falocci , N , Caso , V , Becattini , C , Marcheselli , S , Rueckert , C , Pezzini , A, Morotti , A, Costa , P , Padovani , A, Csiba , L , Szabo , L , Sohn, S-I, Tassinari , T , Abdul-Rahim , A H , Michel , P , Cordier , M , Vanacker , P , Remillard , S, Alberti , A, Venti , M, D'Amore , C , Scoditti , U , Denti , L, Orlandi , G , Chiti , A , Gialdini , G , Bovi , P , Carletti , M , Rigatelli , A, Putaala , J , Tatlisumak , T , Masotti , L , Lorenzini , G , Tassi , R , Guideri , F , Martini , G , Tsivgoulis , G, Vadikolias , K, Liantinioti , C , Corea , F, Del Sette , M , Ageno, W, De Lodovici, M L, Bono, G, Baldi , A, D'Anna , S , Sacco , S, Carolei , A, Tiseo , C , Imberti , D , Zabzuni, D , Doronin , B , Volodina , V , Consoli , D , Galati , F , Pieroni , A , Toni , D , Monaco , S , Baronello , M M , Barlinn , K , Pallesen, L-P, Kepplinger , J , Bodechtel , U , Gerber, J , Deleu, D , Melikyan, G, Ibrahim , F , Akhtar , N , Mosconi , M G \& Lees , K R 2017 , ' Prestroke CHA(2)DS(2)-VASc Score and Severity of Acute Stroke in Patients with Atrial Fibrillation : Findings from RAF Study ', Journal of Stroke \& Cerebrovascular Diseases , vol. 26 , no. 6 , pp. 1363-1368 . https://doi.org/10.1016/j.jstrokecerek

http://hdl.handle.net/10138/297899

https://doi.org/10.1016/j.jstrokecerebrovasdis.2017.02.011

publishedVersion

Downloaded from Helda, University of Helsinki institutional repository.

This is an electronic reprint of the original article.

This reprint may differ from the original in pagination and typographic detail.

Please cite the original version. 


\section{Prestroke $\mathrm{CHA}_{2} \mathrm{DS}_{2}$-VASc Score and Severity of Acute Stroke in Patients with Atrial Fibrillation: Findings from RAF Study}

Monica Acciarresi, MD, ${ }^{1}$ Maurizio Paciaroni, MD, ${ }^{1}$ Giancarlo Agnelli, MD, ${ }^{1}$

Nicola Falocci, PhD, ${ }^{1}$ Valeria Caso, $\mathrm{MD}, \mathrm{PhD},{ }^{1}$ Cecilia Becattini, $\mathrm{MD},{ }^{1}$ Simona Marcheselli, MD, ${ }^{2}$ Christina Rueckert, $\mathrm{MD},{ }^{3}$ Alessandro Pezzini, MD, ${ }^{4}$ Andrea Morotti, MD, ${ }_{4}^{4}$ Paolo Costa, $\mathrm{MD}^{4}$ Alessandro Padovani, MD, PhD, ${ }^{4}$ Laszló Csiba, MD, Lilla Szabó, MD, ${ }^{5}$ Sung-Il Sohn, MD, PhD, ${ }^{6}$

Tiziana Tassinari, MD, ${ }^{7}$ Azmil H. Abdul-Rahim, $\mathrm{MD}^{8}{ }^{8}$ Patrik Michel, PD-MER, ${ }^{9}$ Maria Cordier, MD, ${ }^{9}$ Peter Vanacker, $\mathrm{MD},{ }^{10}$ Suzette Remillard, MD, ${ }^{9}$ Andrea Alberti, MD, ${ }^{1}$ Michele Venti, MD, $\mathrm{PhD}^{1}{ }^{1}$ Cataldo D'Amore, $\mathrm{MD},{ }^{1}$ Umberto Scoditti, MD, ${ }^{11}$ Licia Denti, MD, ${ }^{12}$ Giovanni Orlandi, MD, ${ }^{13}$ Alberto Chiti, MD, ${ }^{13}$ Gino Gialdini, MD, ${ }^{13}$ Paolo Bovi, MD, ${ }^{14}$

Monica Carletti, MD, ${ }^{14}$ Alberto Rigatelli, MD, ${ }^{14}$ Jukka Putaala, MD, ${ }^{15}$ Turgut Tatlisumak, MD, ${ }^{15,16}$ Luca Masotti, MD, ${ }^{17}$ Gianni Lorenzini, MD, ${ }^{17}$ Rossana Tassi, $\mathrm{MD}_{1}{ }^{18}$ Francesca Guideri, $\mathrm{MD},{ }^{18}$ Giuseppe Martini, $\mathrm{MD}_{1}{ }^{18}$

Georgios Tsivgoulis, MD, ${ }^{19,20,21}$ Kostantinos Vadikolias, MD, ${ }^{19}$

Chrissoula Liantinioti, $\mathrm{MD}^{21}$ Francesco Corea, $\mathrm{MD}, \mathrm{PhD},{ }^{22}$

Massimo Del Sette, $\mathrm{MD}^{23}$ Walter Ageno, $\mathrm{MD}^{24}$

Maria Luisa De Lodovici, MD, ${ }^{25}$ Giorgio Bono, MD, ${ }^{25}$ Antonio Baldi, MD, ${ }^{26}$ Sebastiano D'Anna, MD, ${ }^{26}$ Simona Sacco, MD, ${ }^{27}$ Antonio Carolei, ${ }^{27}$ Cindy Tiseo, $\mathrm{MD}^{27}$ Davide Imberti, $\mathrm{MD}^{28}$ Dorjan Zabzuni, $\mathrm{MD}^{28}$ Boris Doronin, $\mathrm{MD}^{29}$ Vera Volodina, ${ }^{29},{ }^{29}$ Domenico Consoli, $\mathrm{MD},{ }^{30}$ Franco Galati, MD, ${ }^{30}$ Alessio Pieroni, MD, ${ }^{31}$ Danilo Toni, MD, PhD, ${ }^{31}$

Serena Monaco, $\mathrm{MD},{ }^{32}$ Mario Maimone Baronello, $\mathrm{MD}^{32}$ Kristian Barlinn, $\mathrm{MD}^{33}$ Lars-Peder Pallesen, $\mathrm{MD}^{33}$

Jessica Kepplinger, MD, ${ }^{33}$ Ulf Bodechtel, $\mathrm{MD}_{1}^{33}$ Johannes Gerber, $\mathrm{MD}_{1}{ }^{33}$

Dirk Deleu, MD, ${ }^{34}$ Gayane Melikyan, MD, ${ }^{34}$ Faisal Ibrahim, MD, ${ }^{34}$

Naveed Akhtar, MD, ${ }^{34}$ Maria Giulia Mosconi, MD, ${ }^{1}$ and Kennedy R. Lees, $\mathrm{MD}^{8}$ 
Background and Purpose: The aim of this study was to investigate for a possible association between both prestroke $\mathrm{CHA}_{2} \mathrm{DS}_{2}$-VASc score and the severity of stroke at presentation, as well as disability and mortality at 90 days, in patients with acute stroke and atrial fibrillation (AF). Methods: This prospective study enrolled consecutive patients with acute ischemic stroke, $\mathrm{AF}$, and assessment of prestroke $\mathrm{CHA}_{2} \mathrm{DS}_{2}$-VASc score. Severity of stroke was assessed on admission using the National Institutes of Health Stroke Scale (NIHSS) score (severe stroke: NIHSS $\geq 10$ ). Disability and mortality at 90 days were assessed by the modified Rankin Scale ( $\mathrm{mRS}<3$ or $\geq 3$ ). Multiple logistic regression was used to correlate prestroke $\mathrm{CHA}_{2} \mathrm{DS}_{2}-$ VASc and severity of stroke, as well as disability and mortality at 90 days. Results: Of the 1020 patients included in the analysis, 606 patients had an admission NIHSS score lower and 414 patients higher than 10. At 90 days, 510 patients had mRS $\geq 3$. A linear correlation was found between the prestroke $\mathrm{CHA}_{2} \mathrm{DS}_{2}$-VASc score and severity of stroke $(P=.001)$. On multivariate analysis, $\mathrm{CHA}_{2} \mathrm{DS}_{2}$-VASc score correlated with severity of stroke $(P=.041)$ and adverse functional outcome (mRS $\geq 3)(P=.001)$. A logistic regression with the receiver operating characteristic graph procedure $(C$-statistics) evidenced an area under the curve of $.60(P=.0001)$ for severe stroke. Furthermore, a correlation was found between prestroke $\mathrm{CHA}_{2} \mathrm{DS}_{2-}$ VASc score and lesion size. Conclusions: In patients with AF, in addition to the risk of stroke, a high $\mathrm{CHA}_{2} \mathrm{DS}_{2}$-VASc score was independently associated with both stroke severity at onset and disability and mortality at 90 days. Key Words: Ischemic stroke- $\mathrm{CHA}_{2} \mathrm{DS}_{2}$-VASc score-severity-outcome-atrial fibrillation-scores. (C) 2017 National Stroke Association. Published by Elsevier Inc. All rights reserved.

From the ${ }^{1}$ Stroke Unit and Division of Internal and Cardiovascular Medicine, University of Perugia, Perugia, Italy; ${ }^{2}$ Neurologia d'urgenza e Stroke Unit, Istituto Clinico Humanitas, Rozzano, Milano, Italy; ${ }^{3}$ Abteilung für Neurologie, Oberschwabenklinik gGmbH, Ravensburg, Germany; ${ }^{4}$ Department of Clinical and Experimental Sciences, Neurology Unit, University "Health and Wealth" of Brescia, Brescia, Italy; ${ }^{5}$ Stroke Unit, University of Debrecen, Debrecen, Hungary; ${ }^{6}$ Department of Neurology, Keimyung University School of Medicine, Daegu, South Korea; ${ }^{7}$ Stroke Unit-Department of Neurology, Santa Corona Hospital, Pietra Ligure, Savona, Italy; ${ }^{8}$ Medical School and Institute of Cardiovascular and Medical Sciences, University of Glasgow, Glasgow, United Kingdom; ${ }^{9}$ Centre Cérébrovasculaire, Service de Neurologie, Département des Neurosciences Cliniques Centre Hopitalier Universitaire Vaudois, Lausanne, Switzerland; ${ }^{10}$ Department of Neurology, Born Bunge Institute, Antwerp University Hospital, Antwerp, Belgium; ${ }^{11}$ Stroke Unit, Neuroscience Department, University of Parma, Parma, Italy; ${ }^{12}$ Stroke Unit, Dipartimento Geriatrico Riabilitativo, University of Parma, Parma, Italy; ${ }^{13}$ Clinica Neurologica, Azienda Ospedaliero-Universitaria, Pisa, Italy; ${ }^{14}$ SSO Stroke Unit, UO Neurologia, DAI di Neuroscienze, AOUI Verona, Italy; ${ }^{15}$ Department of Neurology, Helsinki University Central Hospital, Helsinki, Finland; ${ }^{16}$ Institute of Neuroscience and Physiology, Sahlgrenska Academy at University of Gothenburg and Department of Neurology, Sahlgrenska University Hospital, Gothenburg, Sweden; ${ }^{17}$ Department of Internal Medicine, Cecina Hospital, Cecina, Livorno, Italy; ${ }^{18}$ Stroke Unit, AOU Senese, Siena, Italy; ${ }^{19}$ Department of Neurology, Democritus University of Thrace, University Hospital of Alexandroupolis, Alexandroupolis, Greece; ${ }^{20}$ International Clinic Research Center, St. Anne's University Hospital Brno, Brno, Czech Republic; ${ }^{21}$ Second Department of Neurology, "Attikon" Hospital, University of Athens, School of Medicine, Athens, Greece; ${ }^{22}$ UO Gravi Cerebrolesioni, San Giovanni Battista Hospital, Foligno, Italy; ${ }^{23}$ Stroke Unit, Department of Neurology, Sant'Andrea Hospital, La Spezia, Italy; ${ }^{24}$ Department of Internal Medicine, Insubria University, Varese, Italy; ${ }^{25}$ Stroke Unit, Neurology, Insubria University, Varese, Italy; ${ }^{26}$ Stroke Unit, Ospedale di Portogruaro, Portogruaro, Venice, Italy; ${ }^{27}$ Department of Neurology, University of L'Aquila, L'Aquila, Italy; ${ }^{28}$ Department of Internal Medicine, Ospedale Civile di Piacenza, Piacenza, Italy; ${ }^{29}$ Municipal Budgetary Healthcare Institution of Novosibirsk, City Clinical Hospital \#1, Novosibirsk, Russia; ${ }^{30}$ Stroke Unit, Jazzolino Hospital, Vibo Valentia, Italy; ${ }^{31}$ Department of Neurology and Psychiatry, Sapienza University of Rome, Rome, Italy; ${ }^{32}$ Stroke Unit, Ospedale Civico, Palermo, Italy; ${ }^{33}$ Department of Neurology, Dresden University Stroke Center, Dresden, Germany; and ${ }^{34}$ Neurology, Hamad Medical Corporation, Doha, Qatar.

Received December 14, 2015; revision received January 20, 2017; accepted February 3, 2017.

Disclosures: On behalf of all authors, the corresponding author states that there is no conflict of interest. M. Paciaroni received honoraria as a member of the speaker bureau of Sanofi-Aventis, Boehringer Ingelheim, Bayer, and Pfizer. G. Agnelli received honoraria as a member of the speaker bureau of Boehringer Ingelheim and Bayer. C. Becattini received honoraria as a member of the speaker bureau of Bristol Meyer Squibb and Bayer. P. Michel received Research Grant from the Swiss National Science Foundation and Swiss Heart Foundation; he received speaker fees from Bayer, Boehringer Ingelheim, Covidien, and St. Jude Medical; he received honoraria as advisory relationship from Pierre-Fabre, Bayer, Bristol Meyer Squibb, Amgen, and Boehringer Ingelheim. J. Putaala received honoraria for lectures related to atrial fibrillation and anticoagulants from Orion Pharma, Bristol Meyer Squibb, Pfizer, Bayer, and Boehringer Ingelheim. T. Tatlisumak received honoraria as consultant or advisory relationship from Lundbeck and Boehringer Ingelheim. G. Tsivgoulis received research support from the European Regional Development Fund, Project St. Anne's University Hospital, Brno, and International Clinical Research Center (FNUSA-ICRC) (No. CZ.1.05/1.1.00/02.0123). D. Toni received honoraria as a member of speaker bureau and as advisory board of Boehringer Ingelheim and Bayer. The other authors report no conflicts.

Address correspondence to Monica Acciarresi, MD, Stroke Unit and Division of Internal and Cardiovascular Medicine, University of Perugia, Santa Maria della Misericordia Hospital, Via G. Dottori 1, Perugia 06100, Italy. E-mail: macun77@hotmail.com.

$1052-3057 / \$$ - see front matter

(C) 2017 National Stroke Association. Published by Elsevier Inc. All rights reserved.

http://dx.doi.org/10.1016/j.jstrokecerebrovasdis.2017.02.011 


\section{Background and Purpose}

In patients with atrial fibrillation (AF), current guidelines recommend using the $\mathrm{CHA}_{2} \mathrm{DS}_{2}$-VASc score to assess the risk of stroke. ${ }^{1}$ In retrospective studies, $\mathrm{CHA}_{2} \mathrm{DS}_{2}$ VASc score has been suggested as a predictor of severity of stroke on admission and poor outcome..$^{2-4}$

The aim of this study was to investigate for a possible association between both prestroke $\mathrm{CHA}_{2} \mathrm{DS}_{2}$-VASc score and the severity of stroke at presentation, as well as disability and mortality at 90 days, in patients with acute stroke and AF.

\section{Methods}

Data for this analysis were extracted from the database of a prospective multicenter study which had enrolled consecutive patients with acute stroke and AF (the RAF study). ${ }^{5}$ This study, carried out between January 2012 and March 2014, enrolled 1029 consecutive patients from 29 stroke units throughout Europe and Asia.

Prestroke $\mathrm{CHA}_{2} \mathrm{DS}_{2}$-VASc score was evaluated as previously described. ${ }^{5}$ On admission, the severity of acute stroke was assessed using the National Institutes of Health Stroke Scale (NIHSS); all investigators were certified on the use of this scale. Disability and mortality at 90 days were assessed using the modified Rankin Scale (mRS).

Data on known stroke risk factors were collected as reported in the main paper. ${ }^{5}$

A cerebral computed tomography (CT) or magnetic resonance was performed on admission for all patients to exclude intracranial hemorrhage. A second cerebral CT scan or magnetic resonance was performed 48-72 hours from stroke onset. The sites and sizes of the qualifying infarcts were determined based on standard templates, ${ }^{6,7}$ as previously described. ${ }^{5}$

\section{Statistical Analysis}

The primary prespecified a priori study question was if $\mathrm{CHA}_{2} \mathrm{DS}_{2}$-VASc score had been associated with stroke severity assessed by the NIHSS at onset. Then, as a posthoc analysis, possible correlations between $\mathrm{CHA}_{2} \mathrm{DS}_{2}-$ VASc scores and outcome assessed by mRS and between $\mathrm{CHA}_{2} \mathrm{DS}_{2}$-VASc scores and lesion size were investigated.

The admission NIHSS score was evaluated both as a continuous variable for the correlation coefficient $r$ analysis and as a dichotomized variable (severe stroke NIHSS $\geq 10$ ) for the multivariate analysis.

The correlation coefficient $r$, Pearson product-moment correlation coefficient, was used to measure the strength of the linear association between $\mathrm{CHA}_{2} \mathrm{DS}_{2}$-VASc before the event and NIHSS score on admission (as continuous variable).

Correlations between prestroke $\mathrm{CHA}_{2} \mathrm{DS}_{2}$-VASc and severity of stroke were sought by multiple logistic regression after adjusting for the following variables: smoking, hyperlipidemia, alcohol abuse, and use of statins in addition to $\mathrm{CHA}_{2} \mathrm{DS}_{2}$-VASc.

Thereafter, the probability of a receiver operating characteristic curve against NIHSS $\geq 10$ as dependent variable was plotted. The area under this curve suggests an ability of the $\mathrm{CHA}_{2} \mathrm{DS}_{2}$-VASc score to predict for severe stroke, which is also referred to as the C-statistics (Harrell's C). In addition, a multiple logistic regression model including every single components of the $\mathrm{CHA}_{2} \mathrm{DS}_{2}$-VASc was performed. Stroke was defined as either nondisabling ( $\mathrm{mRS}$ 0-2) or disabling (mRS 3-5).

The factors evaluated as independent predictors of 3-month adverse outcome (defined as $\mathrm{mRS} \geq 3$ or death) were assessed using multiple logistic regression analysis. The variables included in the model were $\mathrm{CHA}_{2} \mathrm{DS}_{2}-$ VASc score, cardiovascular risk factors, reperfusion therapy, and severity of stroke on admission according to the NIHSS score.

The sites and sizes of the qualifying infarcts shown on CT scan were determined based on standard templates as follows: (1) small, when a lesion was $\leq 1.5 \mathrm{~cm}$ in the anterior or posterior circulation; (2) medium, when a lesion was in a cortical superficial branch of the middle cerebral artery (MCA), in the MCA deep branch, in the internal border zone territories, in a cortical superficial branch of the posterior cerebral artery, in the posterior cerebral artery branch, or in a cortical superficial branch of the anterior cerebral artery (ACA); (3) large anterior, when a lesion involved the complete territory of middle cerebral artery (MCA), posterior cerebral artery (PCA), or ACA in 2 cortical superficial branches of MCA, in a cortical superficial branch of MCA associated with the MCA deep branch, or in more than 1 artery territory (e.g., MCA associated with ACA territories); and (4) large posterior, when a lesion was $\geq 1.5 \mathrm{~cm}$ in the brain stem or cerebellum. ${ }^{8}$

A possible correlation between lesion size and $\mathrm{CHA}_{2} \mathrm{DS}_{2}-$ VASc score was investigated using chi-square test $(P$ for trend).

\section{Results}

Overall, 1029 consecutive patients were included in the study (mean age: $77.2 \pm 9.5$ years; 560 females and 469 males). The distribution of $\mathrm{CHA}_{2} \mathrm{DS}_{2}$-VASc score in the study patients is reported in Table 1.

Nine patients were excluded from the analysis as their NIHSS score was not available. Of the 1020 patients included in the analysis, 606 patients had an admission NIHSS score lower and 414 patients higher than 10. The mean NIHSS scores for each of the $\mathrm{CHA}_{2} \mathrm{DS}_{2}$-VASc scores are reported in Table $1(P=.071)$. A linear correlation was found between severity of stroke and $\mathrm{CHA}_{2} \mathrm{DS}_{2}$-VASc score $\left(r^{2}: 0.010, P=.001\right)$ (Fig 1). On multivariate analysis, $\mathrm{CHA}_{2} \mathrm{DS}_{2}$-VASc score correlated with severity of stroke (odds ratio [OR]: 1.084, 95\% confidence interval [CI]: 1.003$1.172, P=.041$, for each 1 -point increase). Considering the 
Table 1. Stroke severity (NIHSS) and 90-day outcome according to prestroke $\mathrm{CHA}_{2} \mathrm{DS}_{2}$-VASc score

\begin{tabular}{|c|c|c|c|}
\hline $\begin{array}{c}\mathrm{CHA}_{2} \mathrm{DS}_{2}-\mathrm{VASc} \\
\text { score }\end{array}$ & $\begin{array}{l}\text { Prestroke } \mathrm{CHA}_{2} \mathrm{DS}_{2} \text {-VASc } \\
\qquad(\mathrm{n}=1029)\end{array}$ & $\begin{array}{l}\text { NIHSS on admission (mean)* } \\
\qquad(\mathrm{n}=1020 \ddagger)\end{array}$ & $\begin{array}{c}\text { 90-day mRS score } \geq 3 \dagger \\
(\mathrm{n}=1019 \S)\end{array}$ \\
\hline 0 & $17(1.7 \%)$ & $5.18 \pm 5.75$ & $4 / 17(23.5 \%)$ \\
\hline 1 & $54(5.2 \%)$ & $8.30 \pm 8.16$ & $16 / 53(30.2 \%)$ \\
\hline 2 & $91(8.9 \%)$ & $8.31 \pm 6.70$ & $34 / 90(37.7 \%)$ \\
\hline 3 & $200(19.4 \%)$ & $8.86 \pm 7.10$ & $81 / 198(40.9 \%)$ \\
\hline 4 & $243(23.6 \%)$ & $9.12 \pm 7.22$ & $125 / 242(51.6 \%)$ \\
\hline 5 & $206(20.0 \%)$ & $9.67 \pm 7.73$ & $113 / 202(55.9 \%)$ \\
\hline 6 & $129(12.8 \%)$ & $9.70 \pm 6.50$ & $78 / 129(60.5 \%)$ \\
\hline 7 & $66(6.4 \%)$ & $10.30 \pm 8.20$ & $43 / 65(66.1 \%)$ \\
\hline $8-9$ & $23(2.2 \%)$ & $12.09 \pm 6.68$ & $16 / 23(69.6 \%)$ \\
\hline
\end{tabular}

Abbreviations: mRS, modified Rankin Scale; NIHSS, National Institutes of Health Stroke Scale.

$* P$ for trend $=.071$.

$\dagger P$ for trend $=.0001$.

$\$$ Nine patients were excluded from the analysis as their NIHSS score was not available.

$\S 1019$ patients were available for the final functional outcome analysis (10 patients were lost to follow-up).

modest correlation, a logistic regression with a receiver operating characteristic graph procedure, to get the $C$-statistics, was performed and it evidenced that the area under the curve was $.60(.56-0.63), P=.0001$ for severe stroke.

When every single components of the $\mathrm{CHA}_{2} \mathrm{DS}_{2}-$ VASc score were assessed for a correlation with stroke severity, only increasing age and female sex were significantly correlated with stroke severity according to NIHSS ( $P=.007$ and $P=.001$, respectively) (Table 2 ).

A correlation was also found between prestroke $\mathrm{CHA}_{2} \mathrm{DS}_{2}$-VASc score and lesion size. After excluding patients treated with revascularization, $70 \%$ of patients with $\mathrm{CHA}_{2} \mathrm{DS}_{2}$-VASc score of 8 or 9 had a medium-large lesion, whereas $70 \%$ of patients with $\mathrm{CHA}_{2} \mathrm{DS}_{2}$-VASc score of 0 had a small lesion (Fig 2, $P$ for trend $=.042$ ).

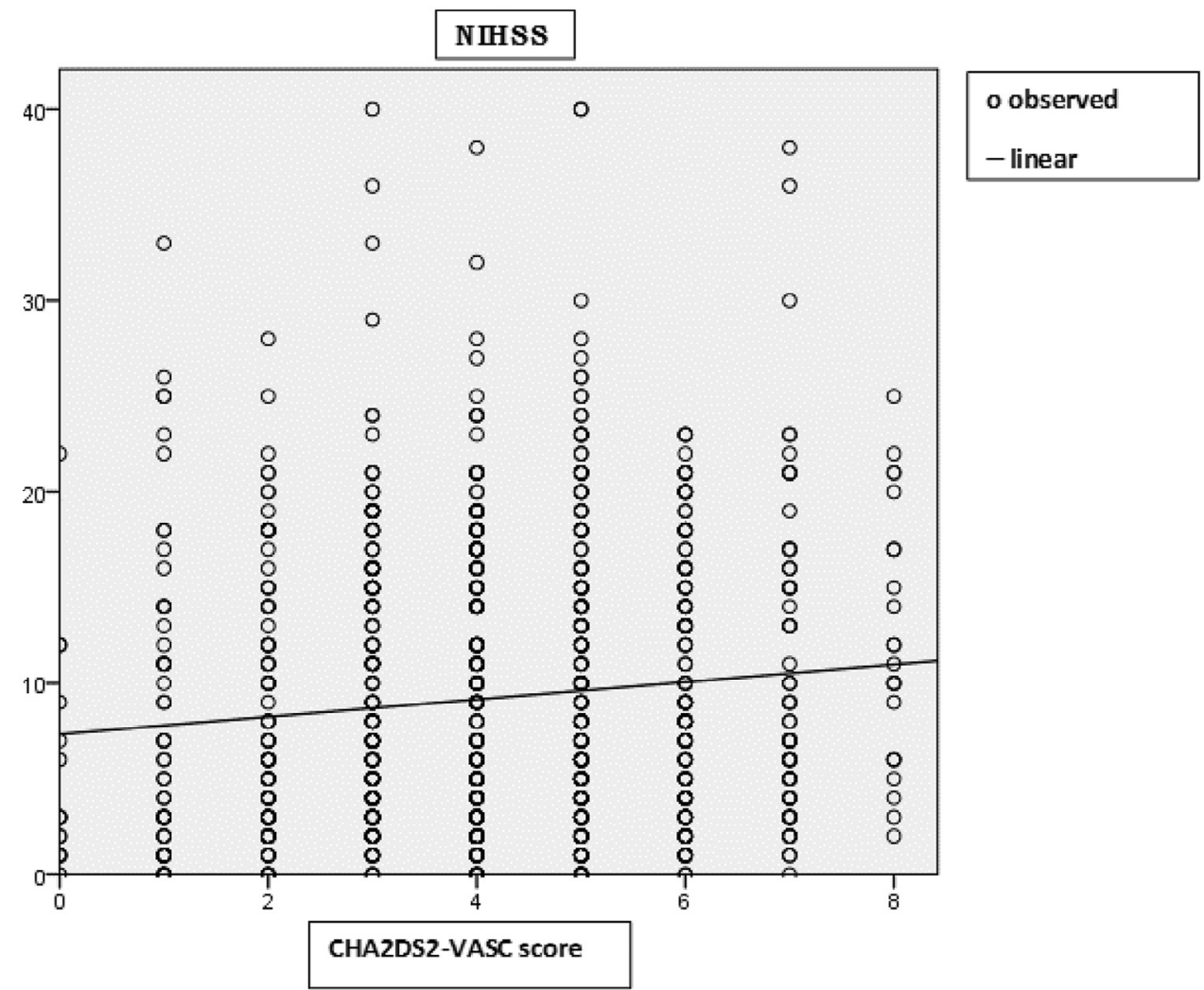

Figure 1. Linear correlation between NIHSS on admission and $\mathrm{CHA}_{2} \mathrm{DS} \mathrm{S}_{2}$-VASc score. Abbreviation: NIHSS, National Institutes of Health Stroke Scale. 
Figure 2. $\mathrm{CHA}_{2} \mathrm{DS} \mathrm{S}_{2}-\mathrm{VASC}$ score and lesion size (excluding patients treated with revascularization). *P for trend $=.042$.

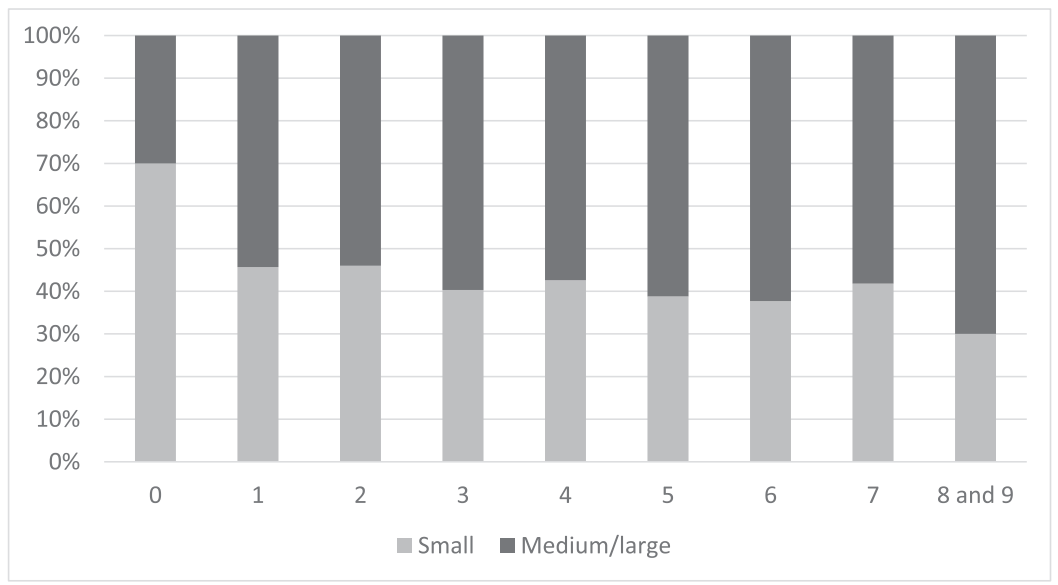

At 90 days, 1019 patients were available for the functional outcome analysis (10 patients were lost to followup). The correlation between prestroke $\mathrm{CHA}_{2} \mathrm{DS}_{2}$-VASc score and 90-day outcome is reported in Table 1.

On multivariate analysis, both NIHSS score on admission and $\mathrm{CHA}_{2} \mathrm{DS}_{2}$-VASc score were correlated with disability and mortality at 90 days (mRS $\geq 3$ ) (OR: 1.236, 95\% CI: 1.197-1.277, P<.0001; OR: 1.278, 95\% CI: 1.100$1.484, P=.001$, respectively, for each point increase).

The administration of thrombolytic therapy and the use of statins on admission correlated with better outcome (OR: .313, 95\% CI: .204-0.481, $P<.0001$; OR: .585, 95\% CI: $.354-0.967, P=.036$, respectively).

\section{Discussion}

The results of our study found correlations between prestroke $\mathrm{CHA}_{2} \mathrm{DS}_{2}$-VASc score and severity of stroke at presentation, according to NIHSS, as well as between $\mathrm{CHA}_{2} \mathrm{DS}_{2}$-VASc score and 90-day mortality and disability, as measured by $\mathrm{mRS}$, therein indicating that a higher $\mathrm{CHA}_{2} \mathrm{DS}_{2}$-VASc score is predictive of a worse outcome.

Moreover, in post-hoc analyses, we found, first, a correlation between higher $\mathrm{CHA}_{2} \mathrm{DS}_{2}$-VASc score and greater

Table 2. Multivariate analysis for correlation of stroke severity and any of each component of $\mathrm{CHA}_{2} D S_{2}$-VASc score

\begin{tabular}{lrrr}
\hline & OR & $P$ & $95 \%$ CI \\
\hline Age (for each year increase) & 1.020 & .007 & $1.005-1035$ \\
Sex & .367 & .001 & $.515-0.175$ \\
Diabetes & 1.172 & .296 & $.870-1.575$ \\
Hypertension & .759 & .110 & $.542-1.065$ \\
Stroke/TIA/thromboembolism & .972 & .849 & $.723-1.306$ \\
$\quad$ history & & & \\
Congestive heart failure & 1.049 & .777 & $.753-1.462$ \\
$\quad$ Vascular disease & 1.034 & .832 & $.760-1.406$ \\
\hline
\end{tabular}

Abbreviations: CI, confidence interval; OR, odds ratio; TIA, transient ischemic attack. lesion size. This finding could support previous studies that have reported an association between $\mathrm{CHA}_{2} \mathrm{DS}_{2}$ VASc score and major vessel occlusion in patients with acute ischemic stroke and AF. ${ }^{9}$ Second, our study results are also in line with past studies reporting that among the risk factors, age and female sex are more predictive of severe stroke. ${ }^{10,11}$

A strength of this study was that several stroke assessment scores were prospectively utilized, and each of these scores was correlated with $\mathrm{CHA}_{2} \mathrm{DS}_{2}$-VASc score, whereas several past studies were retrospective and used only a single assessment score..$^{2-4,12-14}$

In conclusion, we found that an increasing $\mathrm{CHA}_{2} \mathrm{DS}_{2}-$ VASc score in AF patients predicted a more severe stroke at presentation, leading to a higher rate of disability and mortality at 90 days. This result highlights the need for physicians to more regularly investigate for AF in patients with other known vascular risk factors, especially increasing age and female sex.

\section{References}

1. Camm AJ, Lip GYH, De Caterina R, et al. 2012 Focused update of the ESC guidelines for the management of atrial fibrillation: an update of the 2010 ESC guidelines for the management of atrial fibrillation-developed with the special contribution of the European Heart Rhythm Association. Europace 2012;14:1385-1413.

2. Hong HJ, Kim YD, Cha M-J, et al. Early neurological outcomes according to CHADS2 score in stroke patients with non-valvular atrial fibrillation. Eur J Neurol 2012;19:284-290.

3. Giralt-Steinhauer E, Cuadrado-Godia E, Ois Á, et al. CHA(2)DS(2)-VASc score and prognosis in ischemic strokes with atrial fibrillation. J Neurol 2012;259:745-751.

4. Deguchi I, Hayashi T, Ohe Y, et al. The CHA(2)DS(2)VASc score reflects clinical outcomes in nonvalvular atrial fibrillation patients with an initial cardioembolic stroke. J Stroke Cerebrovasc Dis 2013;22:e343-e346.

5. Paciaroni M, Agnelli G, Falocci N, et al. Early recurrence and cerebral bleeding in patients with acute ischemic stroke and atrial fibrillation: effect of anticoagulation and its timing: the RAF study. Stroke 2015;46:2175-2182. 
6. Tatu L, Moulin T, Bogousslavsky J, et al. Arterial territories of human brain: brainstem and cerebellum. Neurology 1996;47:1125-1135.

7. Tatu L, Moulin T, Bogousslavsky J, et al. Arterial territories of the human brain: cerebral hemispheres. Neurology 1998;50:1699-1708.

8. Paciaroni M, Agnelli G, Corea F, et al. Early hemorrhagic transformation of brain infarction: rate, predictive factors, and influence on clinical outcome: results of a prospective multicenter study. Stroke 2008;39:2249-2256.

9. Sakamoto Y, Sato S, Hama Y, et al. The relationship between the pre-admission CHA2DS2-VASc score and proximal artery occlusion in patients with acute stroke and atrial fibrillation. Eur J Neurol 2015;22:1081-1087.

10. Bushnell CD, Lee J, Duncan PW, et al. Impact of comorbidities on ischemic stroke outcomes in women. Stroke 2008;39:2138-2140.
11. Santalucia P, Pezzella FR, Sessa M, et al. Sex differences in clinical presentation, severity and outcome of stroke: results from a hospital-based registry. Eur J Intern Med 2013;24:167-171.

12. Tu HTH, Campbell BCV, Meretoja A, et al. Pre-stroke CHADS2 and CHA2DS2-VASc scores are useful in stratifying three-month outcomes in patients with and without atrial fibrillation. Cerebrovasc Dis 2013;36:273-280.

13. Yaghi S, Sherzai A, Pilot $M$, et al. The CHADS2 components are associated with stroke-related in-hospital mortality in patients with atrial fibrillation. J Stroke Cerebrovasc Dis 2015;24:2404-2407.

14. Tanaka K, Yamada T, Torii T, et al. Pre-admission CHADS2, CHA2DS2-VASc, and R2CHADS2 scores on severity and functional outcome in acute ischemic stroke with atrial fibrillation. J Stroke Cerebrovasc Dis 2015;24:1629-1635. 